Berkala Ilmu Perpustakaan dan Informasi, Vol. 15, No. 1, Juni 2019, Hal. 114-123 DOI: 10.22146/bip.34565

ISSN 1693-7740 (Print), ISSN 2477-0361 (Online)

Tersedia online di https://jurnal.ugm.ac.id/bip

\title{
Kecenderungan topik penelitian di bidang ilmu perpustakaan dan informasi dengan pendekatan Kaidah Zipf
}

\author{
Y. Rudi Kriswanto, Dwi Wahyu Rozanti, Dwininda Kusumawardhani, Eko Noprianto, Ella \\ Erliyana, Ignatius Trisna Setiadi, Zahira Hanifa ${ }^{1}$ \\ ${ }^{1}$ Sekolah Pascasarjana Universitas Gadjah Mada \\ e-mail: y.rudi.k@mail.ugm.ac.id
}

Naskah diterima: 06 April 2018, direvisi: , 10 Desember 2018 disetujui: 12 Februari 2019

\begin{abstract}
ABSTRAK
Pendahuluan.Penelitian ini bertujuan untuk mengetahui kecenderungan peneliti bidang Ilmu Perpustakaan dan Informasi (IPI) pada Berkala Ilmu Perpustakaan dan Informasi UGM.

Metode penelitian.Kajian ini menggunakan metode analisis bibliometrika Kaidah Zipf (penyebaran frekuensi kata), sampel penelitian sebanyak 20 artikel jurnal yang terbit pada tahun 2017.

Data analisis. Setiap artikel dilihat frekuensi kata yang tertinggi, sehingga menghasilkan kata kunci dan subjek untuk setiap artikel, analisis lebih lanjut untuk memperkuat hasil penelitian dilakukan pengelompokan subjek berdasarkan teori Hawkins.

Hasil dan Pembahasan.Hasil dari penelitian ini menunjukkan bahwa kecenderungan topik penelitian pada Berkala Ilmu Perpustakaan dan Informasi UGM pada tahun 2017 terbagi ke dalam dua kelompok yaitu, (1) kelompok kepustakawanan sebanyak 16 artikel; (2) kelompok ilmu informasi sebanyak 4 artikel.

Kesimpulan dan Saran. Topik penelitian di bidang ilmu informasi dan perpustakaan lebih cenderung dominan ke dalam kelompok kepustakawanan. Saran ke depannya adalah peneliti diharapkan mengembangkan penelitian dengan mengangkat topik yang lain.
\end{abstract}

Kata Kunci: Bibliometrika; Ilmu perpustakaan dan informasi;Kaidah zipf

\section{ABSTRACT}

Introduction. This research aims to obtain the mapping of research in the field of Library and Information inBerkala Ilmu Perpustakaan dan Informasi(BIP) published by Universitas Gadjah Mada.

The Research Method.This was abibliometric analysis using Zipf (frequency spread of word) with research samples of 20 jurnal articles published by BIP in 2017.

Data Collection Method. Every article was examined by the highest word frequencyresulting keywords and subjects for each article. Further analysis was conducted to classify subject grouping based on Hawkins theory.

Results and Discussions. The results indicated that research topics in Berkala Ilmu Perpustakaan dan Informasi UGM in 2017 were classified into two categories: (1) There were, 16 articlesrelated to the topic "Librarians", (2) There were 4 articles related to the topic "Information Science". The result is the tendency of research topics in the field of the IPI entered into a group of librarianship.

Conclusion. The research topics in the field of Library and Information Science is more likely to enter the librarianship group. Future advice is that researchers are expected to develop research by raising other topics.

Keywords: Bibliometrics; Library and information science;Zipf's law 


\section{A. PENDAHULUAN}

Ilmu Perpustakaan dan Informasi (IPI) merupakan satu disiplin ilmu yang saat ini semakin menunjukkan perkembangannya seiring dengan kemajuan bidang Teknologi Informasi dan Komunikasi (TIK). Kehadiran TIK semakin memberi kemudahan bagi para peneliti dalam melakukan penelitian. Hal ini memberi pengaruh bagi laju pertumbuhan sebuah disiplin ilmu. Jurnal dan publikasi ilmiah lainnya menjadi salah satu parameter perkembangan ilmu pengetahuan di sebuah institusi, baik institusi pendidikan maupun nonpendidikan, dan diperhitungkan sebagai syarat untuk akreditasi institusi, khususnya institusi pendidikan tinggi (Arief \& Handoko, 2016).

IPI di Indonesia berada di bawah payung keilmuan yang berbeda-beda. Sebagai contoh, IPI di Universitas Padjadjaran berada di bawah Fakultas Ilmu Komunikasi; IPI di Universitas Indonesia IPI Fakultas Ilmu Pengetahuan Budaya; dan seterusnya. Adanya perbedaan ini diduga dapat menimbulkan konsentrasi pengembangan keilmuan yang beragam. Fenomena ini mengantarkan pentingnya untuk melakukan suatu kajian mengevaluasi perkembangan topik penelitian dalam bidang IPI. Salah satu metode yang dapat digunakan dalam penelitian tersebut adalah dengan melakukan kajian bibliometrika. ThomsonReuters (2008) menjelaskan bahwa kajian bibliometrika saat ini digunakan hampir di seluruh dunia untuk mengevaluasi hasil penelitian, terutama pada lembaga pendidikan tinggi (universitas). Bibliometrika merupakan metode yang sering digunakan untuk menggambarkan indikator dalam mengukur perkembangan penelitian ilmiah dalam suatu bidang keilmuan. Rehn et al, (2014) menjelaskan bahwa bibliometrika sering digunakan untuk menilai pola atau kecenderungan penelitian ilmiah melalui kajian kuantitatif.

Kajian bibliometrika didasarkan pada asumsi bahwa sebagian besar penemuan ilmiah dan hasil penelitian yang dipublikasikan dalam sebuah jurnal dapat dibaca dan dikutip oleh peneliti lain. Salah satu pentingnya mengkaji suatu perkembangan penelitian bahwa penelitian terdahulu dapat membawa dampak yang mempengaruhi penelitian selanjutnya. Kajian bibliometrika memiliki 3 kaidah utama diantaranya; Kaidah Bradford, Kaidah Lotka, dan Kaidah Zipf. Kaidah Bradford merupakan kaidah yang digunakan untuk melakukan pengukuran terhadap penyebaran suatu karya berdasarkan distribusi publikasi jurnal. Kaidah Lotka digunakan untuk menghitung produktivitas ilmu yang didasarkan kepada distribusi pengarang dengan frekuensi tertinggi. Selanjutnya, Kaidah Zipf digunakan untuk pengindeksan berdasarkan pada rangking katakata dalam susunan dokumen tertentu yang dihitung berdasarkan frekuensi tertinggi (Hartinah, 2002).

Berdasarkan penelusuran, didapatkan beberapa penelitian tentang Kaidah Zipf. Setyowati (2013) meneliti tentang kecenderungan topik skripsi mahasiswa S1 bidang ilmu perpustakaan di Indonesia periode 2009-2011. Penelitian ini mengkaji abstrak skripsi bidang ilmu perpustakaan pada tiga universitas, yaitu UNAIR, UI, dan USU menggunakan Kaidah Zipf. Penelitian ini menghasilkan beberapa temuan yaitu terdapat beberapa kecenderungan topik penelitian mahasiswa ilmu perpustakaan di Indonesia yaitu library services (11.3\%), the information societies (11\%), serta properties, needs, quality and value of information $(8,58 \%)$.

Setyowati (2017) kembali melakukan penelitian menggunakan Kaidah Zipf dengan tema yang sama. Objek penelitiannya ialah abstrak tesis mahasiswa S2 ilmu perpustakaan di UGM dan UIN Sunan Kalijaga tahun 20142016. Penelitian ini menemukan bahwa trends topik penelitian pada tesis mahasiswa Manajemen Informasi dan Perpustakaan UGM adalah user behavior dan uses of information system dengan persentase $17,7 \%$, sementara di UIN Sunan Kalijaga ialah library description and types dengan persentase $12 \%$.

Qiu et al, (2017) meneliti jurnal informasi dan perpustakaan menggunakan Kaidah Zipf. Jurnal yang diteliti sebanyak 17 jurnal internasional dengan tahun terbit 2008 sampai tahun 2012. Hasil penelitian ini menunjukkan beberapa topik penelitian bidang ilmu informasi 
dan perpustakaan adalah technology, model/models, performance/behavior, systems/system, information technology/information-technology, design, information systems, dan framework.

Berdasarkan beberapa penelitian di atas, terdapat beberapa objek penelitian diantaranya; skripsi IPI, tesis IPI, dan jurnal internasional IPI. Penelitian ini dilakukan pada jurnal nasional IPI. Hal yang dijadikan sebagai objek penelitian adalah kata kunci artikel Jurnal Berkala Ilmu Perpustakaan dan Informasi UGM di tahun 2017 dengan jumlah sebanyak 20 artikel. Salah satu alasan pemilihan artikel yang terbit pada tahun 2017 adalah bahwa artikel ini dinilai sebagai hasil penelitian terbaru dan terupdate. Rumusan masalah dalam penelitian ini adalah bagaimana kecenderungan penelitian bidang IPI pada Berkala Ilmu Perpustakaan dan Informasi pada tahun 2017. Manfaat praktis dari penelitian ini dengan memberikan gambaran tentang kecenderungan penelitian dalam bidang IPI. Gambaran penelitian ini dapat memberikan wacana kepada para peneliti agar mengembangkan keilmuan yang belum banyak dikaji. Manfaat teoritis dari penelitian ini adalah memperkaya kajian bibliometrika dalam bidang IPI.

\section{B. TINJAUAN PUSTAKA Kajian Bibliometrik}

Istilah bibliometrik diperkenalkan oleh Alan Pritchard pada tahun 1969. Roy dan Basak (2013) mendefinisikan bibliometrika sebagai, bibliometrik adalah disiplin di mana metode kuantitatif digunakan untuk menyelidiki proses komunikasi ilmiah dengan mengukur dan menganalisis berbagai aspek dokumen tertulis. Bibliometrik sering digunakan untuk menilai penelitian ilmiah melalui studi kuantitatif. Analisis bibliometrik didasarkan pada asumsi bahwa sebagian besar temuan ilmiah dan hasil penelitian dipublikasikan dalam jurnal ilmiah internasional sehingga dapat dibaca dan dikutip oleh peneliti lain (Rehn et al., 2014).

Menurut Roy dan Basak (2013) kajian bibliometrika bertujuan diantaranya; untuk mengetahui pola penulis, untuk menghitung tingkat kolaborasi, untuk mengetahui statistik distribusi di berbagai bidang ilmu perpustakaan dan informasi, untuk menentukan distribusi geografis dalam jurnal, untuk menampilkan volume penyebaran referensi, dan untuk mengetahui rasio kutipan penulis.

Menurut Pattah (2013) kajian bibliometrika bermanfaat untuk membantu mengevaluasi layanan-layanan perpustakaan, kebijakan pengembangan koleksi, kebijakan perbaikan, pembuatan keputusan, alokasi sumber daya dan juga penyiangan. Data yang diperoleh melalui metode bibliometrika menjadi dasar ilmiah bagi staf perpustakaan dalam membuat keputusan. Kajian bibliometrika juga dianggap sangat bermanfaat untuk analisis kurikulum dan untuk menilai kualitas hasil penelitian. Swain \& Panda (2010) menyatakan bahwa bibliometrik berfungsi sebagai alat dalam mengidentifikasi penulis paling populer dan publikasi potensial. Lebih lanjut, ini membantu dalam menentukan jurnal yang dikutip, peringkat penulis produktif, pola penulis yang produktif, faktor dampak jurnal, dan rincian penting lainnya dari literatur tertentu yang diteliti. Objek kajian bibliometrika dapat dilakukan dengan menganalisis berbagai jenis literatur ilmiah, seperti buku, monograf, laporan penelitian, tesis, disertasi, artikel dalam serial dan periodikal, dan dokumen primer (Pattah, 2013).

\section{Kaidah Zipf}

Kaidah Zipf dapat langsung dan mudah diterapkan untuk setiap set data tanpa komputasi intensif, analisis matematis atau statistik, dan dengan jumlah minimum perhitungan (Hodgson, Lhaopadchan, \& Buakes, 2011). Meskipun demikian, analisis Zipf tidak boleh digunakan prasyarat mutlak dalam analisis data yang sering diabaikan. Proses tersebut bertujuan untuk menghindari kekeliruan dalam melakukan indeks langsung. Kaidah Zipf dapat mengalami kendala yang sangat ketat sehingga lebih baik dilakukan diverifikasi kembali nilai kebenarannya.

Kaidah Zipf harus terhubung pada kekuatan-kekuatan yang bentuk frekuensi dan perubahan bahasa pada umumnya. Piantadosi (2014) menyatakan bahwa Kaidah Zipf pada dasarnya menghitung distribusi kata-kata dalam 
sebuah naskah, namun perlu diingat bahwa perhitungan dengan kaidah Zipf tidak memiliki hal yang istimewa sebagai suatu metode analisis. Hal ini menunjukkan bahwa pengukuran dan pemberian tingkatan pada kata bukan menjadi suatu hal yang utama dalam melihat produktivitas karya ilmiah. Harapannya adalah bahwa review fakta tentang frekuensi kata akan mendorong teori tentang kaidah Zipf untuk mengatasi lebih luas fenomena empiris. Analisis terhadap distribusi frekuensi ini menjadi masalah yang sangat penting untuk ditangani. Kerumitan distribusi frekuensi menjadi faktor penting dalam melakukan pendekatan terkait kaidah Zipf. Distribusi frekuensi kata perhitungan Zipf dalam penelitian ini adalah dengan menggunakan aplikasi wordcounttools.com. Aplikasi tersebut digunakan untuk mengukur ranking pada kata. Persamaan di bawah ini, $r r$ disebut rank frekuensi kata, dan $F(r)$ adalah frekuensi dalam sebuah artikel jurnal. Frekuensi yang diamati sebenarnya akan tergantung pada ukuran artikel jurnal yang diteliti. Kaidah ini menyatakan bahwa frekuensi proporsional adalah kata yang paling sering muncul $(r=1)$ yaitu memiliki proporsional frekuensi 1 .

$$
f(r) \propto \frac{1}{r^{r}}
$$

Pada kasus ini frekuensi kata-kata mengalami perkembangan terus-menerus dan sangat bervariasi. Hal ini menunjukkan bahwa tidak mungkin semua kata sering muncul dalam waktu yang bersamaan. Pada kasus ini, kompleksitas kata, kalimat, paragraf bahkan cerita akan sangat mempengaruhi distribusi frekuensi yang beraneka ragam.

\section{Klasifikasi Kepustakawanan dan Ilmu Informasi}

Artikel yang ditulis oleh Hawkins (2001) dengan judul "Information Science Abstracts: Tracking the Literature of Information Part 1: Definition and Map" menyatakan bahwa betapa tidak mudah mendefinisikan serta membedakan ilmu informasi dengan kepustakawanan. Hal ini terjadi karena adanya perbedaan pendapat di antara beberapa ahli. Donald T Hawkins menawarkan suatu pemahaman untuk membedakan dan membandingkan klasifikasi subjek antara kepustakawanan dengan ilmu informasi. Perbandingan tersebut dapat dilihat pada pada Tabel 1.

\section{METODE PENELITIAN}

Kajian ini menggunakan pendekatan kuantitatif dengan analisis bibliometrik untuk menguji Kaidah Zipf pada produktivitas kata dalam artikel di Jurnal Berkala Ilmu Perpustakaan dan Informasi UGM. Objek kajiannya adalah produktivitas kata yang ada dalam artikel tersebut.

Populasi kajian meliputi 20 artikel yang dimuat di Jurnal Berkala Ilmu Perpustakaan dan Informasi UGM tahun 2017. Analisis data dilakukan dengan langkah-langkah sebagai berikut.

1. Mengukur produktivitas kata pada artikel di Jurnal Berkala Ilmu Perpustakaan dan Informasi UGM dengan Kaidah Zipf. Langkahnya adalah menghitung semua kata kecuali semua angka, nama, dan daftar pustaka yang terdapat dalam artikel tersebut.

2. Menghitung titik transisinya dengan rumus Kaidah Zipf II yang sudah dikembangkan yaitu rumus $\mathrm{ABC}$ sebagai berikut:

$$
\mathrm{Ft}=\frac{-1+\sqrt{1+8 . l_{1}}}{2}
$$

Dengan

$F t=$ titik transisi

$I_{1} \quad$ = jumlah kata yang memiliki frekuensi pengulangan 1

3. Menentukan letak titik transisi dengan cara mengambil sejumlah kata ke atas dan ke bawah dengan jarak yang sama, sehingga akan diperoleh sejumlah kata yang dijadikan kata kunci atau indeks. Kata kunci atau indeks ini adalah bukan berupa kata sandang (ini, itu, the, an, $a$, dan sejenisnya); bukan berupa kata sambung (adalah, dan, is, are dan sejenisnya), serta awalan. Istilah semacam itu, dalam pengindeksan disebut sebagai stop list sehingga diusahakan untuk dihindari ataupun dibuang. 
2. Setelah ditemukan kata kunci, langkah selanjutnya melakukan klasifikasi subjek berdasarkan teori Hawkins yaitu pengelompokan kepustakawanan dan ilmu informasi.

\section{HASILDAN PEMBAHASAN}

Pada pembahasan ini dibagi menjadi 4 diantaranya; perhitungan kata, letak titik transisi, klasifikasi subjek, dan kecenderungan topik.

\section{Perhitungan Produktivitas Kata}

Hasil perhitungan dari 20 artikel ditemukan perhitungan kata diantaranya; jumlah total kata, jumlah kata berlainan (unik), jumlah kata paling banyak muncul, jumlah kata yang muncul 1 kali, dan nilai titik transisi. Titik transisi didapatkan dengan cara mensubstitusikan nilai $I_{I}$ kedalam rumus. Rumus menghitung titik transisi adalah sebagai berikut:

$$
F_{t}=\frac{-1 \pm \sqrt{1+8 \cdot I_{1}}}{2}
$$

Sebagai contoh, untuk menghitung titik transisi pada artikel 1 . Nilai $I_{l}$ pada artikel 1 sebesar 337, sehingga apabila nilai tersebut disubstitusikan menjadi seperti ini:

$$
F_{t}=\frac{-1 \pm \sqrt{1+8 \cdot(337)}}{2}
$$

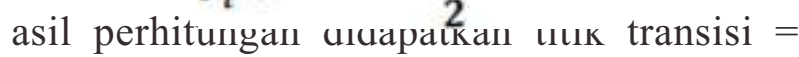
25,46. Perhitungan serupa dilakukan untuk artikel 2 hingga artikel 20. Tabel 2 menunjukkan perhitungan untuk 20 artikel tersebut.

\section{Letak Titik Transisi}

Setelah ditemukan titik transisi, selanjutnya menentukan letak titik transisi pada perhitungan produktivitas kata. Nilai titik transisi artikel 1 pada tabel 2 sebesar $\mathbf{2 5 , 4 6}$. Nilai ini terletak diantara frekuensi 25 dan 68 , atau terletak diantara kata "kajian" dan "bahwa". Berdasarkan pengambilan jarak 12 keatas diperoleh kata:pemustaka, dalam, di, kepuasan, terhadap, ini, dengan, fasilitas, informasi, untuk, layanan, bahwa. Selanjutnya berdasarkan pengambilan jarak 12 ke bawah diperoleh kata: kajian, sumber, pada, psikologi, tinggi, studi, memuaskan, program, daya, rata, aspek, sarana. Kata-kata tersebut dapat digunakan sebagai kata kunci pada artikel ini, kecuali untuk kata hubung atau kata sandang. Hasil pemilihan kata menghasilkan kata kunci yaitu; pemustaka, kepuasan, terhadap, fasilitas, informasi, layanan, kajian, sumber, psikologi, tinggi, studi, memuaskan, program, daya, rata, aspek, sarana. Tabel 3 menunjukkan frekuensi kata yang sudah diambil dengan jarak 12 ke atas dan 12 ke bawah dari titik transisi.

Cara yang serupa digunakan untuk menentukan letak titik transisi untuk artikel 2 sampai artikel 20. Data pada Tabel 4 menunjukkan temuan kata kunci yang diperoleh dari letak titik transisi.

\section{Klasifikasi Subjek}

Berdasarkan hasil temuan kata kunci, selanjutnya dilakukan klasifikasi subjek berdasarkan Teori Hawkins. Teori Hawkins sebelumnya telah dijelaskan pada bab tinjauan pustaka. Tabel 5 menunjukkan subjek dari perolehan kata kunci yang telah dikelompokkan berdasarkan Teori Hawkins.

\section{Kecenderungan Topik}

Hasil dari penentuan pengelompokan atau kecenderungan subjek selanjutnya dihitung b e rdas arkan pe nge lom pok a n "kepustakawanan" dan "ilmu informasi". Tabel 6 menunjukkan perhitungan jumlah artikel berdasarkan kelompok dan subjek.

Berdasarkan hasil pembahasan, diperoleh bahwa kecenderungan ke 20 artikel lebih banyak kepada kelompok kepustakawanan dengan jumlah 16 artikel, sedangkan untuk kelompok Ilmu Informasi didapatkan 4 artikel.

\section{E. KESIMPULAN}

Hasil kajian ini dapat disimpulkan bahwa berdasarkan kata kunci, topik penelitian pada Jurnal Berkala Ilmu Perpustakaan dan Informasi UGM tahun 2017 memiliki kecenderungan subjek kepustakawanan sebanyak 16 artikel dan kecenderungan subjek Ilmu Informasi sebanyak 4 artikel. Berdasarkan perhitungan jumlah artikel, persentase subjek kepustakawanan 
sebesar $80 \%$, sementara persentase subjek ilmu informasi sebesar 20\%. Hasil kajian ini diharapkan penelitian di bidang Ilmu Perpustakaan dan Informasi lebih memperbanyak khasanah keilmuan yang berkaitan dengan topik ilmu informasi.

\section{DAFTAR PUSTAKA}

Arief, I., \& Handoko. (2016). Jurnal online dengan Open Journal System. Padang: Lembaga Pengembanggan Teknologi Informasi dan Komunikasi Universitas Andalas.

Hartinah, S. (2002). Penggunaan Dalil Zipf pada pengindeksan otomatis. In Kumpulan Makalah Kursus Bibliometrika: Masyarakat Informetrika Sosial. Depok.

Hawkins, D. T. (2001). Information science abstracts: tracking the literature of information science. Part 1: Definition and Map. Journal of the American Society for Information Science, 52(1), 44-53. https://doi.org/https://doi.org/10.1002/153 $2-2890(2000) 52: 1<44:$ : A I D ASI1057>3.0.CO;2-6.

Hodgson, A., Lhaopadchan, S., \& Buakes, S. (2011). How informative is he Thai Corporate Governance Index? a Financial Approach. International Journal of Accounting and Information Management, 19(1), 53-79. https://doi.org/ $10.1108 / 18347641111105935$

Pattah, S. H. (2013). Pemanfaatan kajian bibliometrika sebagai metode evaluasi dan kajian dalam ilmu perpustakaan dan informasi. Jurnal Ilmu Perpustakaan \& Informasi KHIZANAH AL-HIKMAH, 1(1), 47-57.

Piantadosi, S. T. (2014). Zipf's word frequency law in natural language: A critical review and future directions. Psychonomic Bulletin and Review, 21(5), 1112-1130. https:// doi.org/10.3758/s13423-014-0585-6

Qiu, J., Zhao, R., Yang, S., \& Dong, K. (2017). Informetrics: theory, methods and applications. in Informetrics: Theory, Methods and Applications (pp. 1-438). https://doi.org/10.1007/978-981-10-40320 .
Rehn, C., Gornitzki, C., Larsson, A., \& Wadskog, D. (2014). Bibliometric handbook for Karolinska Institute. Karolinska Institutet. Swedia: Thomson $\mathrm{R}$ e u t e r s . R e t r i e v ed from https://kib.ki.se/sites/default/files/bibliome tric handbook 2014.pdf. Diakses $15 / 0 \overline{3} / 2018$.

Roy, S. M., \& Basak, M. (2013). Journal of documentation: A bibliometric study. Library Philosophy Practices (e-Journal), (945), 1-10. Retrieved from http://digitalcommons.unl.edu/cgi/viewco ntent . cgi article $=2313 \&$ context $=$ libphilpr ac. Diakses 10/03/2018.

Setyowati, R. (2013). Kecenderungan topik skripsi mahasiswa S1 bidang ilmu perpustakaan di Indonesia periode 20092011 (suatu studi bibliometrika pada abstrak skripsi mahasiswa Program Studi Ilmu Perpustakaan UNAIR, UI,dan USU). Skripsi, Universitas Airlangga.

Setyowati, R. (2017). Trends topik penelitian bidang ilmu perpustakaan: analisis bibliometrika-Zipf's Law pada abstrak tesis mahasiswa S2 ilmu perpustakaan di Universitas Gadjah Mada dan UIN Sunan Kalijaga tahun 2014-2016. Tesis, Universitas Islam Negeri Sunan Kalijaga.

Swain, D. K., \& Panda, K. C. (2010). Journal of intellectual property rights, 2002-2010: s bibliometric study. Chinese Librarianship: An International Electronic Journal, 33, $1-12$.

Thomson-Reuters. (2008). Whitepaper using bibliometrics: a guide to evaluating research performance with citation data. In Thomson Reuters. Philadhelpia: Thomson $\mathrm{R}$ e u t e r s . R e tri e v e d from http://ips.clarivate.com $/ \mathrm{m} / \mathrm{pdfs} / 325133$ _th omson.pdf. Diakses 11/03/2018. 


\section{DAFTAR TABEL}

Tabel 1. Subjek Kepustakawanan vs Subjek Ilmu Informasi Sumber: -Hawkins (2001)

\begin{tabular}{cc}
\hline Librarianship subjects & Information science subjects \\
\hline Archives & Artificial intelligence, expert systems \\
Buildings & Basic information science research \\
Exhibition & Behavioral sciences \\
Furniture & Fuzzy logic/fuzzy searching \\
Library organization & Information industry/marketplace \\
Library use and user & Information professionals \\
Loans & Information technologies technical aspects (i.e. computing, internet, \\
telecommunications) \\
Management, budgeting, finance \\
Materials \\
Microforms \\
Museums & Law/legislation/regulation \\
Nonprint materials & Reading processing \\
Old and rare materials & Subject area database \\
Promotion & Types of literature \\
Removals & \\
Type of library staff & \\
Users (various types) & \\
Vehicles & \\
World Librarianship & \\
\end{tabular}

Tabel 2. Tabel perhitungan produktivitas kata untuk 20 artikel

\begin{tabular}{|c|c|c|c|c|c|c|}
\hline \multirow[b]{2}{*}{ Tahun } & \multirow[b]{2}{*}{ Artikel } & \multicolumn{5}{|c|}{ Jumlah Kata } \\
\hline & & Total & Berlainan & $\begin{array}{c}\text { Paling Banyak } \\
\text { Muncul }\end{array}$ & $\begin{array}{c}\text { Muncul } 1 \text { Kali } \\
\left(\mathrm{I}_{1}\right)\end{array}$ & $\begin{array}{l}\text { Nilai Titik } \\
\text { Transisi }\end{array}$ \\
\hline \multirow{20}{*}{2017} & 1 & 2607 & 635 & 81 & 337 & 25,46 \\
\hline & 2 & 4129 & 899 & 192 & 489 & 30,77 \\
\hline & 3 & 4648 & 1438 & 181 & 879 & 41,43 \\
\hline & 4 & 4922 & 968 & 221 & 477 & 30,40 \\
\hline & 5 & 3214 & 718 & 183 & 375 & 26,88 \\
\hline & 6 & 3071 & 808 & 179 & 445 & 29,33 \\
\hline & 7 & 2614 & 678 & 109 & 321 & 24,83 \\
\hline & 8 & 4140 & 1000 & 178 & 520 & 31,75 \\
\hline & 9 & 4404 & 1000 & 136 & 563 & 33,05 \\
\hline & 10 & 3669 & 749 & 171 & 398 & 27,71 \\
\hline & 11 & 3128 & 925 & 78 & 672 & 36,16 \\
\hline & 12 & 3570 & 949 & 96 & 536 & 32,24 \\
\hline & 13 & 2553 & 923 & 62 & 547 & 32,58 \\
\hline & 14 & 3225 & 658 & 104 & 328 & 25,11 \\
\hline & 15 & 4071 & 842 & 204 & 430 & 28,83 \\
\hline & 16 & 3319 & 834 & 139 & 448 & 29,43 \\
\hline & 17 & 3539 & 790 & 128 & 455 & 29,67 \\
\hline & 18 & 5007 & 1201 & 219 & 647 & 35,47 \\
\hline & 19 & 3550 & 949 & 131 & 527 & 31,97 \\
\hline & 20 & 3953 & 1067 & 228 & 627 & 34,91 \\
\hline
\end{tabular}

Sumber: Data primer diolah tahun 2017 
Tabel 3. Tabel letak titik transisi pada artikel 1

\begin{tabular}{|c|c|}
\hline Kata & Frekuensi \\
\hline pemustaka & 71 \\
\hline dalam & 59 \\
\hline di & 53 \\
\hline kepuasan & 47 \\
\hline terhadap & 37 \\
\hline ini & 34 \\
\hline dengan & 32 \\
\hline fasilitas & 30 \\
\hline informasi & 29 \\
\hline untuk & 28 \\
\hline layanan & 26 \\
\hline bahwa & 26 \\
\hline kajian & 25 \\
\hline sumber & 25 \\
\hline pada & 24 \\
\hline psikologi & 23 \\
\hline tinggi & 23 \\
\hline studi & 23 \\
\hline memuaskan & 22 \\
\hline program & 21 \\
\hline daya & 21 \\
\hline rata & 20 \\
\hline aspek & 19 \\
\hline sarana & 19 \\
\hline
\end{tabular}

Sumber: Data primer diolah tahun 2017 
Tabel 4. Temuan kata kunci untuk 20 artikel

\begin{tabular}{|c|c|}
\hline Artikel & Kata Kunci \\
\hline 1 & $\begin{array}{l}\text { pemustaka, kepuasan, terhadap, fasilitas, informasi, layanan, kajian, sumber, psikologi, tinggi, studi, } \\
\text { memuaskan, program, daya, rata, aspek, sarana }\end{array}$ \\
\hline 2 & $\begin{array}{l}\text { literatur, pemanfaatan, karya, ugm, perpustakaan, fakultas, sitiran, hasil, majalah, disitir, kajian, } \\
\text { koleksi, artikel }\end{array}$ \\
\hline 3 & data, riset, open, makalah, peneliti, hasil \\
\hline 4 & variabel, pegawai, kependidikan, penelitian, batas, orang, lama, data, korelasi \\
\hline 5 & $\begin{array}{l}\text { wilayah, program, kelompok, penelitian, rural, aktivitas, mojo, nglanduk, urban, warurejo, } \\
\text { implementasi Indonesia }\end{array}$ \\
\hline 6 & informasi, literasi, pustakawan, perpustakaan, variabel, model, penelitian, baik, kemampuan \\
\hline 7 & $\begin{array}{l}\text { perpustakaan, informasi, penelitian, sumber, sampel, klaster, akademika, kebutuhan, karya, fakultas, } \\
\text { pemustaka, jurnal, koleksi, ilmiah, ugm }\end{array}$ \\
\hline 8 & perpustakaan, digital, penelitian, informan, informasi, hasil, data, materi, yogyakarta, stikes \\
\hline 9 & $\begin{array}{l}\text { informasi, pembelajaran, learning, mahasiswa, online, pustakawan, digital, pendidikan, elektronik, } \\
\text { memiliki }\end{array}$ \\
\hline 10 & $\begin{array}{l}\text { pengaruh, kerja, signifikan, informasi, nilai, penelitian, pemustaka, perpustakaan, hasil, melakukan, } \\
\text { rata, sumbangan }\end{array}$ \\
\hline 11 & $\begin{array}{l}\text { perpustakaan, penduduk, pedesaan, kelompok, penelitian, masyarakat, hasil, kegiatan, informasi, } \\
\text { lumbung, membaca, padi, unsur }\end{array}$ \\
\hline 12 & $\begin{array}{l}\text { sistem, kelas, sejarah, perpustakaan, ilmu, nomor, bahan, koleksi, history, pustaka, penelitian, bidang, } \\
\text { subkelas, }\end{array}$ \\
\hline 13 & indonesia, riset, lingkungan, negara, kolaborasi, internasional, nasional, hasil \\
\hline 14 & hasil, nilai, jurnal, penghitungan bidang, data, buletin, ilmu, count, ugm \\
\hline 15 & $\begin{array}{l}\text { penelitian, referens, penelusuran, kebutuhan, kecemasan, virtual, membantu, pencarian, menyedia kan, } \\
\text { individu }\end{array}$ \\
\hline 16 & $\begin{array}{l}\text { kolaborasi, publikasi, internasional, korelasi, jumlah, data, karya, negara, internal, penelitian, jurnal, } \\
\text { domestik, individu }\end{array}$ \\
\hline 17 & $\begin{array}{l}\text { ugm, penelitian, hukum, mahasiswa, buku, disertasi, inggris, tesis, data, ketersediaan, bahasa, fakultas, } \\
\text { skripsi, law, lokal, westlaw, informasi }\end{array}$ \\
\hline 18 & $\begin{array}{l}\text { pustakawan, kompetensi, perpustakaan, ugm, kerja, anggota, informasi, kemampuan, profesionalisme, } \\
\text { tugas, sikap, pengetahuan, organisasi }\end{array}$ \\
\hline 19 & perpustakaan, informan, kegiatan, penelitian, masyarakat, tambak, buku, lo rok, warga, membaca \\
\hline 20 & buku, toko, pembeli, pengelola, pemasaran, produk \\
\hline
\end{tabular}

Sumber: Data primer diolah tahun 2017 
Tabel 5. Klasifikasi subjek berdasarkan Teori Hawkins

\begin{tabular}{ccc}
\hline Artikel & $\begin{array}{c}\text { Kelompok (Kepustakawanan / } \\
\text { Ilmu Informasi }\end{array}$ & Keterangan Subjek \\
\hline $\mathbf{1}$ & Kepustakawanan & Library use and user \\
$\mathbf{2}$ & Kepustakawanan & Materials \\
$\mathbf{3}$ & Kepustakawanan & Materials \\
$\mathbf{4}$ & Kepustakawanan & Type of library staff \\
$\mathbf{5}$ & Ilmu Informasi & Reading \\
$\mathbf{6}$ & Ilmu Informasi & Reading \\
$\mathbf{7}$ & Kepustakawanan & Materials \\
$\mathbf{8}$ & Kepustakawanan & Nonprint materials \\
$\mathbf{9}$ & Kepustakawanan & Library use and user \\
$\mathbf{1 0}$ & Kepustakawanan & Users (various types) \\
$\mathbf{1 1}$ & Kepustakawanan & Library use and user \\
$\mathbf{1 2}$ & Kepustakawanan & Materials \\
$\mathbf{1 3}$ & Kepustakawanan & Exhibition \\
$\mathbf{1 4}$ & Kepustakawanan & Materials \\
$\mathbf{1 5}$ & Ilmu Informasi & Behavioral sciences \\
$\mathbf{1 6}$ & Kepustakawanan & Exhibition \\
$\mathbf{1 7}$ & Kepustakawanan & Materials \\
$\mathbf{1 8}$ & Kepustakawanan & Type of library staff \\
$\mathbf{1 9}$ & Ilmu Informasi & Reading \\
$\mathbf{2 0}$ & Kepustakawanan & Promotion \\
\hline
\end{tabular}

Sumber: Data primer diolah tahun 2017

Tabel 6. Tabel perhitungan jumlah artikel berdasarkan kelompok dan subjek

\begin{tabular}{cccc}
\hline $\begin{array}{c}\text { Kelompok (Kepustakawanan / } \\
\text { Ilmu Informasi) }\end{array}$ & Subjek & \multicolumn{2}{c}{ Jumlah } \\
\hline & Library use and user & 3 & \\
& Materials & 6 & \\
Type of library staff & 2 & \multirow{2}{*}{16} \\
Kepustakawanan & Nonprint materials & 1 & \\
& Users (various types) & 1 & \\
& Exhibition & 2 & \\
& Promotion & 1 & \\
& Reading & 3 & \multirow{2}{*}{4} \\
\hline Ilmu Informasi & Behavioral sciences & 1 & \\
\end{tabular}

Sumber: Data primer diolah tahun 2017 